\title{
AVALIAÇÃO DO EFEITO DA SEROTONINA (5-HT) E DA MONOABLAÇÃO DO PEDÚNCULO OCULAR NA INDUÇÃO DA MATURAÇÃO OVARIANA DE Penaeus penicillatus (ALCOCK, 1905)
}

\author{
OLIVEIRA, P. S. P. ${ }^{1}$ e CORRÊA, A. M. A. ${ }^{2}$ \\ ${ }^{1}$ Instituto de Ciências Biológicas, Universidade Católica do Salvador, \\ Av. Pinto de Aguiar, s/n, Campus de Pituaçu, Salvador, BA \\ ${ }^{2}$ Departamento de Zoologia, Instituto de Biologia, UFBA, Av. Ademar de Barros, s/n, \\ Campus Universitário, Ondina, CEP 40170-290, Salvador, BA \\ Correspondência para: Angélica Maria Araújo Corrêa, Departamento de Zoologia, Instituto de Biologia, UFBA, \\ Av. Ademar de Barros, s/n, Campus Universitário, Ondina, CEP 40170-290, Salvador, BA, e-mail: angelica@ufba.br \\ Recebido em 03/03/98 - Aceito em 04/09/98 - Distribuído em 30/06/99
}

(Com 1 figura)

\section{ABSTRACT \\ Evaluation of the effect of serotonin (5-HT) and eyestalk monoablation on the induction of ovary maturation in Penaeus Penicillatus (Alcock, 1905)}

The effects of serotonin and of the monoablation of eyestalk on the induction of gonadal development of Penaeus penicillatus (red tail shrimp) were investigated. Immature females with an average weight of $20 \mathrm{~g}$ were selected and ramdonly distributed into four groups of 5 animals as follows: initial control group (IC), sacrificed at the $1^{\text {st }}$ day of the experiment; parallel control group (CG), injected with $0.05 \mathrm{ml}$ of saline solution; monoablated group (AG), submitted to monoablation at day 0 and injected with $0.05 \mathrm{ml}$ of saline immediatelly after the monoablation and on the $5^{\text {th }}$ day; serotonin group (SG), injected with $0.05 \mathrm{ml}$ of serotonin, dissolved in saline solution, both on day 0 on the $5^{\text {th }}$ day, in a total dose of $15 \mu \mathrm{g}$ per gram of animal's weight $\left(7,74 \times 10^{-7} \mathrm{~mol}\right)$. Animals were sacrificed on day 0 for the initial control group (IC), and on the $5^{\text {th }}, 10^{\text {th }}$ and $15^{\text {th }}$ days for the other groups. A fragment from the front lobe of the animal's gonad was fixed in aqueous Bouin and processed with the usual optic microscopy techniques. Analyses consisted of a morphological description of cells and measurements of the diameter of oocytes, which gave evidence to the stimulating role of serotonin and of monoablation on gonad maturation. The statistical analysis (Anova - SNK, P < 0.05) of the diameter values of oocytes showed monoablation to be more effective in inducing ovary maturation than serotonin at the concentration used $\left(7,74 \times 10^{-7} \mathrm{~mol}\right)$.

Key words: Penaeus sp., serotonin, 5-HT, reproduction, ovary maturation.

\section{RESUMO}

O efeito da serotonina e da monoablação do pedúnculo ocular na indução do desenvolvimento gonadal de Penaeus penicillatus (camarão do rabo vermelho) foi investigado. Fêmeas imaturas com peso médio de $20 \mathrm{~g}$ foram selecionadas e distribuídas de maneira aleatória em quatro grupos de 5 animais com uma réplica para cada grupo: grupo controle inicial (CI), sacrificado no 1 o dia do experimento; grupo controle paralelo (GC), injetado com $0,05 \mathrm{ml}$ de solução salina; grupo monoablado (GA), submetido à monoablação no dia 0 e injetado com $0,05 \mathrm{ml}$ de solução salina logo após a monoablação e no 5 dia; grupo serotonina (GS), injetado com $0,05 \mathrm{ml}$ de serotonina dissolvida em solução salina no dia 0 e $5^{\circ}$ dia, numa dose total de $15 \mu \mathrm{g}$ por grama de peso do animal $\left(7,74 \times 10^{-7} \mathrm{~mol}\right)$. Os animais do grupo controle inicial (CI) foram sacrificados no dia 0 , e no $5^{\circ}, 10^{\circ}$ e $15^{\circ}$ dias para os demais grupos, respectivamente. Fragmentos dos lóbulos anteriores das gônadas dos animais foram fixados em Bouin 
aquoso e processados com as técnicas usuais de microscopia óptica. As análises consistiram na descrição morfológica das células e na medida do diâmetro dos ovócitos, evidenciando um papel estimulador da serotonina e da monoablação sobre a maturação gonadal. A análise estatística (Anova SNK, P < 0,05) dos valores de diâmetro dos ovócitos mostrou ser a monoablação mais efetiva na indução da maturação ovariana que a serotonina na concentração utilizada $\left(7,74\right.$ x 10 $\left.0^{-7} \mathrm{~mol}\right)$.

Palavras-chave: Penaeus sp., serotonina, 5-HT, reprodução, maturação ovariana.

\section{INTRODUÇÃO}

Nos cultivos comerciais, a manutenção de estoques de animais requer uma disponibilidade constante de fêmeas maduras, sendo de fundamental importância a indução da maturação ovariana na continuidade desse processo.

A indução do desenvolvimento gonadal em cativeiro envolve a manipulação combinada de fatores endócrinos, nutricionais e ambientais (Bueno, 1989). Por sua vez, a manipulação endócrina comumente utilizada na indução da maturação ovariana em cativeiro é a monoablação do pedúnculo ocular.

A existência de um fator estimulante da gônada tem sido também registrada, e evidências demonstram que os gânglios cerebróide e torácico produzem o hormônio estimulador da gônada (Hinsch \& Bennett, 1979; Eastman Recks \& Fingerman, 1984, Takayanagi, et al., 1986).

Por sua vez, as dificuldades inerentes ao processo de monoablação e os avanços no conhecimento dos mecanismos neuroendócrinos da reprodução têm estimulado a busca, pelos pesquisadores, de alternativas para a indução hormonal da maturação ovariana. Assim, tem-se investigado o envolvimento de outros hormônios no processo reprodutivo, a exemplo de um precursor do hormônio juvenil (metil farnesoato), sintetizado no órgão mandibular, e de ecdisteróides produzidos no órgão-Y (Meusy \& Payen, 1988). Yano (1985), trabalhando com Metapenaeus ensis, mostrou que a progesterona induz a maturação ovariana e a desova, enquanto Sarojini et al. (1995a), utilizando técnicas in vivo e in vitro, mostrou resultados que reforçam a hipótese da ação do hormônio concentrador do pigmento vermelho (HCPV) como um neurotransmissor que estimula a liberação do hormônio estimulador da gônada em Procambarus clarkii.

Estudos mais recentes têm investigado o papel de neurotransmissores na liberação de neurohor- mônios em crustáceos (Keller \& Bayer, 1968; Rao \& Fingerman, 1970; Arechiga et al., 1985; Mattson \& Spaziani, 1985; Fingerman \& Rosenberg, 1988; Richardson et al., 1991; Kulkarni \& Fingerman, 1992), sendo registrado o papel da serotonina neste processo (Richardson et al., 1991; Kulkarini \& Fingerman, 1992; Sarojini et al., 1995b).

Embora a literatura indique alguns estudos alternativos na indução da maturação ovariana em cativeiro, a técnica ainda utilizada é a monoablação do pedúnculo ocular que, apesar do registro de dados conflitantes, como aqueles registrados por Chamberlain \& Lawrence (1981 apud Browdy, 1992); Emmerson (1980); Browdy \& Samocha (1985), foi amplamente assimilada pelas fazendas de camarão. Por outro lado, os estudos alternativos utilizando a manipulação hormonal, bem como o uso de neurotransmissores, necessitam de maior aprofundamento.

Assim, visando contribuir para o conhecimento dos mecanismos reprodutivos em P. penicillatus (camarão do rabo vermelho), este trabalho teve por objetivo comparar o efeito da serotonina e da monoablação do pedúnculo ocular na indução do desenvolvimento gonadal.

\section{MATERIAL E MÉTODO}

Fêmeas de $P$. penicillatus (camarão do rabo vermelho) foram capturadas durante a despesca de um dos viveiros de engorda da Fazenda Experimental Oruabo (distrito de Acupe, município de Santo Amaro da Purificação, Bahia) e transferidas para tanques circulares com capacidade de 10.0001 , com uma coluna d'água de $0,5 \mathrm{~m}$ e aeração constante. Os animais foram alimentados duas vezes ao dia, com uma dieta composta de siris (Callinectes sp.) e bebe-fumo (Anomalocardia brasiliana) na própria concha, numa proporção de $20 \%$ da biomassa.

Os tanques eram limpos diariamente, retirando-se os restos de alimento e de exúvias (quando 
presentes), procedendo-se também a troca de $100 \%$ do volume d'água.

Os parâmetros físico-químicos foram medidos diariamente durante o período do experimento (janeiro e fevereiro de 1996), obtendo-se valores médios de $28^{\circ} \mathrm{C}$ para a temperatura, $32 \%$ para a salinidade e 8 para o $\mathrm{pH}$.

Após o período de aclimatação (48 h), fêmeas imaturas com peso médio de $20 \mathrm{~g}$ foram selecionadas e agrupadas de maneira aleatória em 4 grupos de 5 animais, com uma réplica para cada grupo. As réplicas foram realizadas com intervalo de 24 horas e mantidas no mesmo tanque, sendo esses animais identificados através do uso de anéis de silicone colorido (adaptado de Tsuzuki et al., 1994) inseridos na base do pedúnculo ocular.

Os animais do grupo controle (GC) receberam injeções de $0,05 \mathrm{ml}$ de solução salina (Cole, 1941 apud Welsh \& Smith, 1953) via intra-hemocele (mediante punção da membrana artrodial da articulação do $5^{\circ}$ par de pereiópodos) no dia 0 e no 5 o dia.

Animais do grupo monoablados (GA) foram submetidos à extirpação unilateral de um dos pedúnculos oculares, em sua base, com o auxílio de uma tesoura de ponta fina. Esses animais (grupo GA) receberam injeções de $0,05 \mathrm{ml}$ de solução salina no dia $0, \operatorname{logo}$ após a monoablação, e no $5^{\circ}$ dia. As fêmeas do grupo serotonina (GS) receberam injeções de $0,05 \mathrm{ml}$ de serotonina ( 5 HT, 5-hidroxitriptoamina, complexo de sulfato de creatinina, SIGMA) dissolvida em solução salina no dia 0 e no $5^{\circ}$ dia, numa dose total de $15 \mu \mathrm{g}$ por grama de peso do animal $\left(7,74 \times 10^{-7} \mathrm{~mol}\right)$.

O grupo controle inicial (CI) foi sacrificado no dia 0 (zero) e os demais grupos foram sacrificados no $5 \circ$, $10^{\circ}$ e $15^{\circ}$ dias, respectivamente. Fragmentos do lóbulo anterior da gônada foram retirados, fixados em Bouin aquoso por 24 horas e processados de acordo com a metodologia usual para microscopia óptica. Para as análises histológicas utilizou-se um microscópio Leitz-Biomed. As medidas do diâmetro dos ovócitos foram baseadas no contorno dos ovócitos, desenhados com o auxílio de câmara clara, sendo tomados uma média de 50 ovócitos por animal, medidos em milímetros ( $\mathrm{mm})$, utilizando-se um escalímetro de precisão marca Tridente. A conversão de $\mathrm{mm}$ em $\mu \mathrm{m}$ foi feita com base na lâmina com régua padrão de 0,01 e $0,1 \mathrm{~mm}$ (B\&L).
Os dados de medida dos diâmetros dos ovócitos para cada grupo foram tratados estatisticamente pelo teste de análise de variância ANOVA, seguido do teste para comparação de médias múltiplas Student-Newman-Keuls (SNK) $(\mathrm{P}<0,05)$ utilizando-se o programa estatístico "Statistical Package for Social Sciences - SPSS" (Nie et al., 1975).

\section{RESULTADOS}

As análises histológicas dos fragmentos do tecido ovariano para os grupos controles e tratados (Tabela 1) possibilitaram a descrição das seguintes características:

Grupo controle inicial (CI) - este grupo de animais foi o que apresentou o menor desenvolvimento gonadal entre os grupos avaliados, com predominância de células primordiais e ovócitos jovens. Raros ovócitos em pré-vitelogênese foram visualizados em algumas lojas ovarianas localizadas nas regiões mais periféricas do ovário.

Grupo controle paralelo (GC) - este grupo evidenciou menor desenvolvimento ovariano que o grupo serotonina (GS) e monoablado (GA), apresentando características similares ao do grupo controle inicial (CI).

Para os animais sacrificados no $5^{\circ}$ e $10^{\circ}$ dias, observou-se a presença de ovócitos jovens e em pré-vitelogênese na região mais periférica, sendo este último em maior proporção para os animais sacrificados no $10^{\circ}$ dia. Nesses grupos, o desenvolvimento ovariano apresentou-se similar, com $90 \%$ dos animais no estádio imaturo e $10 \%$ em estádio de maturação inicial.

Animais sacrificados no 15 dia apresentaram-se com gônadas mais desenvolvidas do que as dos animais sacrificados no $5^{\circ}$ e no $10^{\circ}$ dias. O estroma ovariano mostrou-se organizado, formando pequenas lojas limitadas por células foliculares, com predominância de ovócitos pré-vitelogênicos. Foram também observados ovócitos em vitelogênese (com citoplasma de aspecto flocoso, presença de vacúolos e iniciando-se em alguns ovócitos a transição ácido/basófila).

Neste grupo, $37,5 \%$ dos animais apresentaram ovários imaturos e $62,5 \%$, ovários em maturação inicial. 
TABELA 1

Resumo das características histológicas do tecido ovariano por grupos de tratamento e estádios de maturação gonadal predominante.

\begin{tabular}{|c|c|c|}
\hline Grupos animais & Características do estroma ovariano & $\begin{array}{l}\text { Estádios de } \\
\text { maturação } \\
\text { predominante }\end{array}$ \\
\hline $\begin{array}{l}\text { Controle inicial } \\
\quad \text { dia } 0\end{array}$ & $\begin{array}{l}\text { Estroma ovariano com células germinativas em desenvolvimento, } \\
\text { apresentando grande número de células primordiais e ovócitos } \\
\text { jovens. }\end{array}$ & Imaturo \\
\hline Controle $5^{\circ}$ dia & $\begin{array}{l}\text { Aspecto similar ao controle inicial. Apresentam também ovócitos } \\
\text { jovens em pequenos grupos envoltos por células foliculares. }\end{array}$ & Imaturo \\
\hline Controle $10^{\circ}$ dia & $\begin{array}{l}\text { Gônadas apresentando ovócitos em diferentes fases de } \\
\text { crescimento, observando-se proliferação de células foliculares } \\
\text { limitando grupo de ovócitos. Predominância de ovócitos jovens, } \\
\text { registrando-se alguns poucos ovócitos em pré-vitelogenese nas } \\
\text { regiões mais periféricas das lojas ovarianas, em número superior } \\
\text { aos dos animais do } 5^{\circ} \text { dia. }\end{array}$ & Imaturo \\
\hline Controle $15^{\circ}$ dia & $\begin{array}{l}\text { Gônadas em desenvolvimento com predominância de ovócitos em } \\
\text { pré-vitelogênese. Alguns ovócitos vitelogênicos iniciando a } \\
\text { transição ácido/basófila são também evidenciados. }\end{array}$ & Maturação inicial I \\
\hline Monoablado $5^{\circ}$ dia & $\begin{array}{l}\text { Gônadas caracterizadas pelo grande número de ovócitos em pré- } \\
\text { vitelogênese e ovócitos ácido/basófilos. }\end{array}$ & Maturação inicial II \\
\hline Monoablado $10^{\circ}$ dia & Estroma ovariano similar ao do grupo monoablado do $5^{\circ}$ dia. & Maturação inicial II \\
\hline Monoablado $15^{\circ}$ dia & $\begin{array}{l}\text { Gônadas bastante desenvolvidas predominando ovócitos em pré- } \\
\text { vitelogênese e ovócitos vitelogênicos com citoplasma acidófilo. }\end{array}$ & Maturação avançada \\
\hline Serotonina $5^{\circ}$ dia & $\begin{array}{l}\text { Gônadas apresentando ovócitos em diferentes tamanhos de } \\
\text { crescimento, com predominância de células primordiais e ovócitos } \\
\text { jovens formando grupos limitados por células foliculares. Alguns } \\
\text { ovócitos em pré-vitelogênese são evidenciados nas regiões } \\
\text { periféricas. }\end{array}$ & Imaturo \\
\hline Serotonina $10^{\circ}$ dia & Similar ao do grupo serotonina do $5^{\circ}$ dia. & Imaturo \\
\hline Serotonina $15^{\ominus}$ dia & $\begin{array}{l}\text { Gônadas apresentando pequenas lojas limitadas por células } \\
\text { folicurares. Predominância de ovócitos em pré-vitelogênese, } \\
\text { observando-se também alguns ovócitos iniciando uma mudança } \\
\text { ácido/basófila. }\end{array}$ & Maturação inicial II \\
\hline
\end{tabular}

$\mathrm{GC}$ = grupo controle paralelo (salina); GA = grupo monoablado (salina e monoablação); GS = grupo serotonina (5-HT na concentração $7,74 \times 10^{-7} \mathrm{~mol} /$ animal).

Grupo monoablado (GA) - Os animais sacrificados no $5^{\circ}$ dia apresentaram as gônadas bastante desenvolvidas quando comparadas às dos grupos controle e serotonina (GS) no mesmo período de tempo.

Observou-se grande número de ovócitos em pré-vitelogênese e também alguns ovócitos com citoplasma de aspecto flocoso contendo pequenos vacúolos. Em alguns animais verificou-se a presença de ovócitos ácido/basófilos. Neste grupo, $80 \%$ dos animais apresentaram-se com gônadas em estádio de maturação média, $10 \%$ em estádio de maturação avançada e 10\% com gônadas apresentando grande número de folículos que sofreram reabsorção com células foliculares hipertróficas.

Para os animais sacrificados no $10^{\circ} \mathrm{dia}$, as gônadas evidenciaram predominância de ovócitos em pré-vitelogênese e em vitelogênese. Foram também observados, além dos grupos de ovócitos jovens envolvidos por células foliculares, ovócitos pré-vitelogênicos e vitelogênicos envoltos individualmente por células foliculares. Neste grupo, 
$80 \%$ dos animais encontravam-se com as gônadas em estádio de maturação média e $20 \%$ apresentaram gônadas com grande número de folículos que sofreram reabsorção e com células foliculares hipertróficas, semelhantes aos $10 \%$ dos animais do grupo monoablado sacrificados no $5^{\circ}$ dia.

Os animais sacrificados no $15^{\circ}$ dia apresentaram gônadas bastante desenvolvidas, com ovócitos em pré-vitelogênese e vitelogênese, havendo predominância de ovócitos em vitelogênese avançada, sendo este último de citoplasma acidófilo. Este grupo apresentou o maior desenvolvimento gonadal dentre todos os grupos avaliados. Neste grupo, 33,4\% dos animais atingiram estádio gonadal de maturação média e $66,6 \%$, o estádio de maturação avançada.

Grupo serotonina (GS) - Animais sacrificados no $5^{\circ}$ e $10^{\circ}$ dias evidenciaram gônadas com ovócitos em diferentes fases de desenvolvimento, predominando células primordiais e ovócitos jovens, formando grupos limitados por células foliculares. Nas regiões periféricas de algumas lojas ovarianas observaram-se também ovócitos em pré-vitelogênese. Neste grupo, $88,8 \%$ dos animais apresentaram-se no estádio imaturo e apenas $11,2 \%$, em maturação inicial.

Para os animais sacrificados no $15^{\circ}$ dia, registrou-se a predominância de ovócitos em pré-vitelogênese, observando-se também ovócitos com citoplasma de aspecto bastante flocoso e alguns ovócitos iniciando uma mudança ácido/basófila. Neste grupo, $22,3 \%$ dos animais permaneceram com gônadas no estádio imaturo e $77,7 \%$ apresentaram gônadas em maturação média.
A Tabela 2 apresenta os valores médios dos diâmetros dos ovócitos no grupo de animais sacrificados no $5^{\circ}$ dia.

Esses valores apresentam-se próximos, entretanto estatisticamente pode-se observar a formação de dois agrupamentos: um formado pelos grupos controle paralelo (GC), controle inicial (CI) e monoablado (GA), que não apresentam diferenças significativas entre as médias, e outro formado pelos grupos monoablado (GA) e serotonina (GS). Sendo que o grupo monoablado (GA) apresenta valores médios que o situa no limite superior do primeiro grupo e inferior do segundo. $\mathrm{O}$ grupo serotonina difere significativamente dos grupos controle inicial (CI) e paralelo (GC).

Já no grupo de animais sacrificados no $10^{\circ}$ dia (Tabela 3 ) pode-se observar três agrupamentos que diferem significativamente entre si $(\mathrm{P}<0,05)$. O grupo controle (GC), que apresenta o menor valor, e o grupo monoablado (GA), com o maior valor, formam grupos distintos, enquanto os grupos controle inicial (CI) e serotonina (GS) formam um único grupo com valores intermediários. $\mathrm{O}$ grupo monoablado (GA) passa agora a apresentar valores médios superiores ao do grupo serotonina (GS), invertendo uma tendência apresentada para o 5o dia. É observado também que o grupo controle paralelo (GC) apresenta valores médios inferiores aos do grupo controle inicial (CI). Apesar de os valores médios do grupo controle (GC) no $10^{\circ}$ dia serem menores que no 5 o dia, não existe diferença significativa entre esses dois grupos, o mesmo ocorrendo para o grupo serotonina (GS), quando se comparam os valores médios do 5 o e do $10^{\circ}$ dia.

TABELA 2

Média do diâmetro dos ovócitos em $\mu \mathrm{m}(\mathrm{X} \pm \mathrm{S})$, analisados para os grupos sacrificados no 5 dia. $^{\circ}$

\begin{tabular}{|c|c|c|}
\hline Grupos de tratamento & $\begin{array}{l}\text { Número de } \\
\text { animais }\end{array}$ & Diâmetro médio dos ovócitos $(\mu \mathrm{m})$ \\
\hline Controle inicial $(\mathrm{CI})^{*}$ & 05 & $38,87 \pm 1,08$ \\
\hline Grupo controle paralelo (GC)* & 10 & $38,74 \pm 1,27$ \\
\hline Grupo monoablados (GA) & 08 & $40,23 \pm 1,35$ \\
\hline Grupo serotonina (GS)* & 09 & $40,86 \pm 1,28$ \\
\hline
\end{tabular}

$\mathrm{CI}=$ grupo controle inicial; $\mathrm{GC}=$ grupo controle paralelo (salina); GA = grupo monoablado (salina e

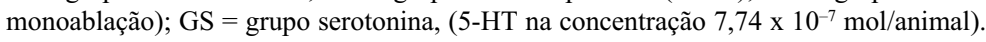

$(*)$ Diferem significativamente (ANOVA - SNK, P $<0,05$ ). 
No caso de animais sacrificados no $15^{\circ}$ dia (Tabela 4) observa-se a confirmação da tendência verificada no $10^{\circ}$ dia, com o grupo monoablado (GA) constituindo-se como um grupo independente, com valores médios bem superiores aos dos outros grupos.

O grupo serotonina (GS) aparece como o segundo grupo mais desenvolvido, formando também um grupo independente.

Os grupos controle inicial (CI) e controle paralelo (GC) não apresentam diferenças entre as médias, entretanto o grupo controle paralelo apresenta agora valores médios superiores ao do controle inicial, revertendo uma tendência que se apresentou desde o $5^{\circ}$ dia.

\section{DISCUSSÃO}

Os resultados dos bioensaios objetivando a avaliação do efeito da serotonina e da monoablação do pedúnculo ocular na indução da maturação ovariana em $P$. penicillatus (camarão do rabo vermelho) mostraram que todos os animais utilizados ao longo do experimento (grupo controle (GC), grupo monoablado (GA) e grupo serotonina (GS)) deram início ao processo reprodutivo, indicando assim que as fêmeas selecionadas se encontravam no estádio adulto, aptas para o início e o desenvolvimento do processo reprodutivo.

Comparando-se os grupos experimentais com o grupo controle observa-se que os grupos serotonina e monoablado mostraram maior desenvolvimento gonadal que o grupo de animais controle, evidenciado pelo maior diâmetro dos ovócitos e por suas características histológicas (Tabela $1 \mathrm{e}$ Fig. 1). Entretanto, ao comparar os grupos experimentais monoablado (GA) e serotonina (GC), observa-se que o grupo monoablado foi o que mostrou maior desenvolvimento no processo de maturação gonadal, alcançando em menor período de tempo o estádio de maturação avançada (Tabela 1).

TABELA 3

Média do diâmetro dos ovócitos em $\mu \mathrm{m}(\mathrm{X} \pm \mathrm{S})$, analisados para os grupos sacrificados no $10^{\circ}$ dia.

\begin{tabular}{|lccc|} 
Grupos de tratamento & $\begin{array}{c}\text { Número de } \\
\text { animais }\end{array}$ & Diâmetro médio dos ovócitos $(\boldsymbol{\mu m})$ \\
\hline Grupo controle paralelo (GC)* & 05 & 10 & $38,87 \pm 1,08$ \\
\hline Grupo monoablado (GA)* & 08 & $37,24 \pm 1,25$ \\
\hline Grupo serotonina (GS) & 09 & $42,96 \pm 1,25$ \\
\hline
\end{tabular}

$\mathrm{CI}=$ grupo controle inicial; $\mathrm{GC}=$ grupo controle paralelo (salina); $\mathrm{GA}=$ grupo monoablado (salina e

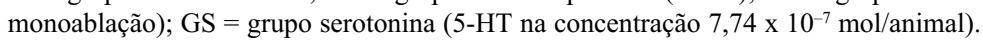

(*) Diferem significativamente (ANOVA - SNK, P <0,05).

TABELA 4

Média do diâmetro dos ovócitos em $\mu \mathrm{m}(\mathrm{X} \pm \mathrm{S})$, analisados para os grupos sacrificados no $15^{\circ}$ dia.

\begin{tabular}{|lccc|} 
Grupos de tratamento & & $\begin{array}{c}\text { Número de } \\
\text { animais }\end{array}$ & Diâmetro médio dos ovócitos $(\boldsymbol{\mu m})$ \\
\hline Controle inicial (CI) & 05 & $38,87 \pm 1,08$ \\
\hline Grupo controle paralelo (GC) & 06 & $41,89 \pm 1,08$ \\
\hline Grupo monoablados (GA)* & 06 & $126,71 \pm 1,19$ \\
Grupo serotonina (GS)* & 08 & $48,37 \pm 1,13$ \\
\hline
\end{tabular}

$\mathrm{CI}=$ grupo controle inicial; $\mathrm{GC}=$ grupo controle paralelo (salina); $\mathrm{GA}=$ grupo monoablado (salina e

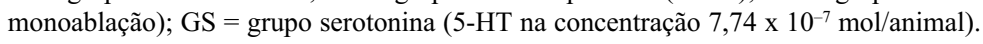

$\left(^{*}\right)$ Diferem significativamente (ANOVA - SNK, $\mathrm{P}<0,05$ ). 


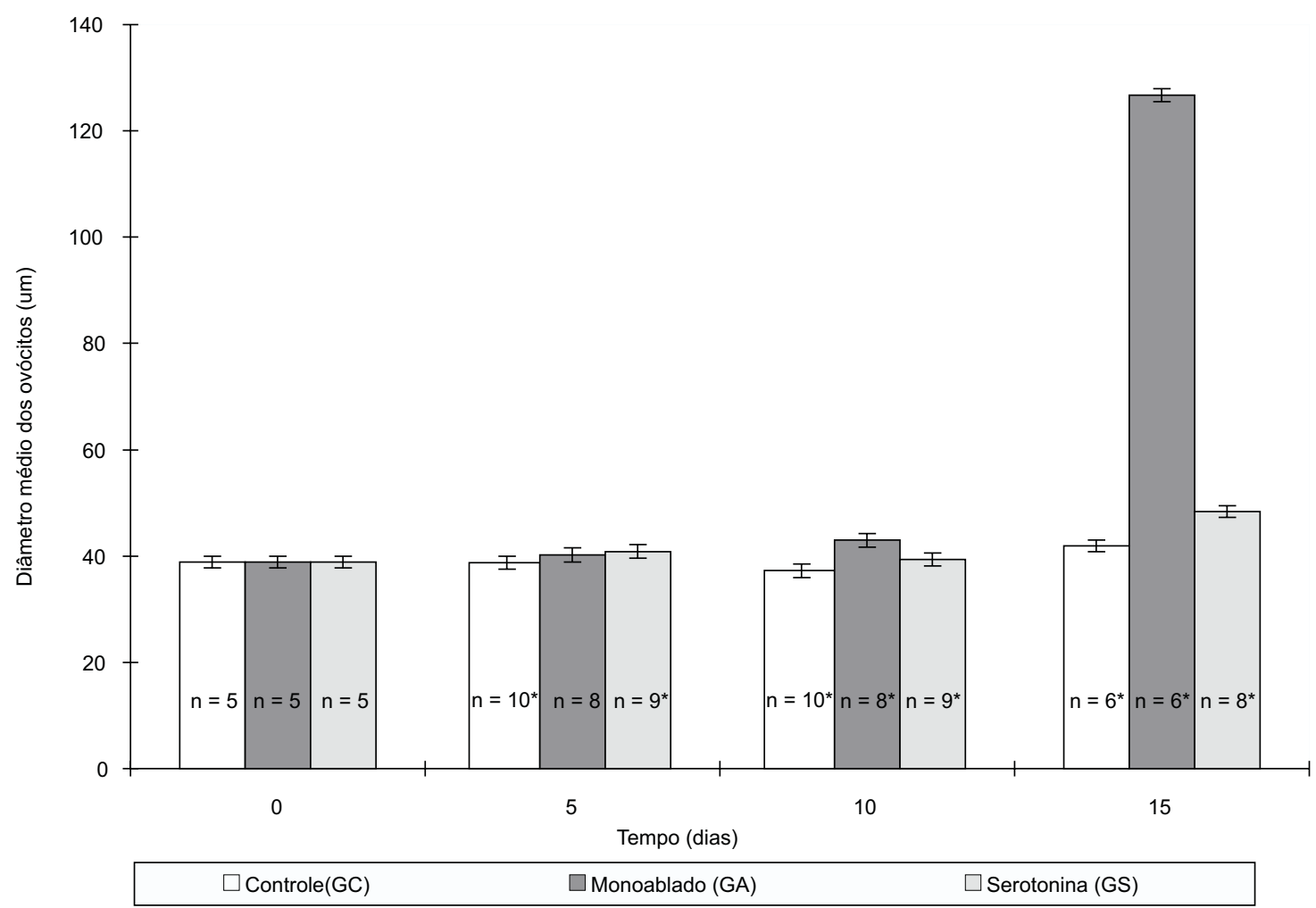

Fig. 1 - Penaeus penicillatus. Diâmetro médio dos ovócitos $(\mathrm{X} \pm \mathrm{S})$, para os grupos de animais sacrificados nos dia $0(\mathrm{CI}=$ controle inicial) e no 5ำ, $10^{\circ}$ e $15^{\circ}$ dias $(\mathrm{GC}=$ grupo controle paralelo; GA = grupo monoablado; GS = grupo serotonina). (*) Diferem significativamente (ANOVA - SNK, P $<0,05$ ).

O efeito acelerador da reprodução pela monoablação do pedúnculo ocular em peneídeos tem sido referenciado desde os trabalhos de Idyll (1971) em $P$. duorarum. Estudos posteriores têm evidenciado o papel indutor da monoablação do pedúnculo ocular para acelerar a maturação, a produção de ovos e a freqüência de desovas entre as mudas, além de induzir o encurtamento do ciclo de muda (Emmerson, 1980; Browdy \& Samocha, 1985; Browdy et al., 1986).

Uma vez que o pedúnculo ocular é a fonte do hormônio inibidor da gônada, é provável que sua retirada, com conseqüente redução deste hormônio, interfira num possível processo de feedback entre o hormônio inibidor (HIG) e o hormônio estimulador (HEG) da gônada, de modo que a liberação do hormônio estimulador por esse suposto processo seja mais efetiva que a sua liberação pela serotonina.

Além de ter alcançado maior desenvolvimento gonadal, o grupo de animais monoablados apresentou também maior variação nos resultados, principalmente para os grupos do $5^{\circ}$ e do $10^{\circ}$ dias, em que um percentual de $10 \%$ dos animais apresentaram estádios avançados e cerca de $30 \%$ apresentaram gônadas com folículos que sofreram reabsorção.

Evidência histológica da reabsorção de ovócitos tem sido referenciada em $P$. duorarum por Martosubroto (1974). Emmerson (1980), estudando a maturação induzida em $P$. indicus, aborda a reabsorção de ovócitos em decorrência do ciclo de muda. É possível que essas variações sejam decorrentes de características fisiológicas intrínsecas de cada animal, principalmente por tratar de uma população alóctone (criada exclusivamente em cativeiro).

Também é possível que tais variações possam ser atribuídas ao estádio de muda em que esses animais sofreram a monoablação, uma vez que muda e reprodução são processos intrínsecos e regulados por hormônios que atuam de forma antagônica (Weitzman, 1964; Cheung, 1966, 1969; Adiyody, 1968, 1985; Van Herp, 1992). 
Em relação à indução ovariana pela serotonina, os resultados foram significativos para os animais sacrificados no $15^{\circ}$ dia, registrando-se um estádio ovariano mais avançado (maturação inicial II) quando comparado aos animais do grupo controle (maturação inicial I) no mesmo período de tempo (Tabela 1).

O efeito estimulador da serotonina (5-HT), na maturação ovariana, tem sido demonstrado para outras espécies de crustáceos, a exemplo de Uca pugilator (Richardson et al., 1991) e Procambarus clarkii (Kulkarni et al., 1992; Kuljarni \& Fingerman, 1992; Sarojini et al., 1995b).

O modo de ação da serotonina no processo de indução da maturação dos ovócitos não foi objeto de investigação deste trabalho. Entretanto, a literatura tem registrado o estímulo da serotonina na liberação de diversos hormônios, tais como o hormônio hiperglicemiante (Keller \& Bayer, 1968), o hormônio dispersante do pigmento vermelho (Rao \& Fingerman, 1970), o hormônio neurodepressor (Arechiga et al., 1985) e o hormônio inibidor da muda (Mattson \& Spaziani, 1985). Investigando o papel da serotonina na indução da maturação ovariana em Uca pugilator, Richardson et al. (1991) aventam o papel indireto da serotonina para estimular a liberação do hormônio estimulador da gônada, o que foi confirmado posteriormente pelas investigações de Kulkarni et al. (1992) para Procambarus clarkii in vivo e por Sarojini et al. (1995b) in vitro nesta mesma espécie. Richardson et al. (1991), utilizando substâncias bloqueadoras de 5-HT, confirmaram sua ação endógena no desenvolvimento ovariano.

Ainda em relação à serotonina, Richardson et al. (1991) observaram, em Uca pugilator, que o efeito da serotonina é dose-dependente, registrando ser esta uma característica típica de sistema regulado por hormônio. Para U. pugilator foi registrado o estímulo indutor da serotonina sobre a maturação ovariana, em doses iguais ou superiores a $1,25 \times 10^{-8} \mathrm{~mol} /$ animal. Para $P$. penicillatus não foi investigada a relação dose-dependência, entretanto a concentração de $7,74 \times 10^{-7} \mathrm{~mol} / \mathrm{ani}$ mal utilizada foi efetiva, com resultados similares àqueles registrados para Procambarus clarkii (Kulkarni et al., 1992) na mesma concentração e período de tempo.

Embora a literatura não registre um estudo comparativo entre a indução da maturação ovariana pela injeção de serotonina e a técnica da monoablação do pedúnculo ocular, os resultados aqui apresentados evidenciam ser a monoablação mais efetiva na indução da maturação gonadal que a serotonina na concentração utilizada. (Tabela 1 e Fig. 1.)

De acordo com os resultados aqui apresentados, a utilização da serotonina como método de indução da maturação ovariana ainda demanda maiores investigações, entretanto os resultados obtidos até o momento mostram-se promissores e, de acordo com Browdy (1992), à medida que novos estudos sobre o efeito de neurotransmissores na reprodução de crustáceos preencherem as lacunas existentes a respeito do mecanismo de ação dessas substâncias, uma indução farmacológica da vitelogênese pode ser possível.

Agradecimentos - À Fazenda Oruabo, Bahia Pesca S/A, por gentilmente nos ceder os animais e permitir a realização de parte deste trabalho em suas instalações. Aos laboratórios de Histopatologia (CPGM, Fiocruz, Ba), Malacologia e Ecologia de Bentos (IB, UFBa) e Biologia Marinha (IB, UFBa) pela utilização de equipamentos.

\section{REFERÊNCIAS BIBLIOGRÁFICAS}

ADIYODI, R. G., 1968, Protein metabolism in relation to reproduction and moulting in the crab, Paratelphusa hydrodomus (Herbst). 1. Eletrophoretic studies on the mode of utilization of solube proteins during vitllogenesis. Indian J. Exp. Biol., 6: 144-147.

ADIYODI, R. G., 1985, Reproduction and its control. Academic Press Inc., New York, v. 9, Integument, Pigments and Hormonal Process, Biol. of Crustacea, pp. 147-215.

ARECHIGA, H., FLORES, J. \& GARCIA, U., 1985, Biosynthesis and release of the crustacean neurodepressing hormone. In: B. Lofts \& W. N. Holmes (eds.), Current Trends in comparative Endocrinology, Hong Kong, Hong Kong University Press, pp. 787-91.

BROWDY, C. L., 1992, A review of the reproductive biology of Penaeus species: pespectives on controlled shrimp maturation systems for high quality nauplii production. Proceedings of the Special Session on Shrimp Farming. In: The World Aquacult. Soc., pp. 22-51.

BROWDY, C. L., HADANI, A., SAMOCHA, T. M. \& LOYA, Y., 1986, The reproductive performance of wild and pond-reared Penaeus semisulcatus de Haan. Aquaculture, 59: 251-58.

BROWDY, C. L. \& SAMOCHA, T. M., 1985, The effect of eyestalk ablation on spawning, molting and mating of Penaeus semisulcatus De Haan. Aquaculture, 49: 19-29.

BUENO, S. L. S., 1989, Fechamento do ciclo de vida do camarão branco Penaeus schmitti Burkenroad, 1936 (Crustacea, Decapada, Penaeidae), sob condições de cultivo em escala comercial. Tese de Doutorado, Universidade de São Paulo, São Paulo, 146p. 
CHEUNG, T. S., 1966, The interrelations among three hormonal-controled characters in adult female shore crab, Carcinus maena (L.). Biol. Bull. Mar. Biol., 130: 59-66.

CHEUNG, T. S., 1969, The enviromental and hormonal control of growth and reproduction in the adult female stone crab, Menippe mercenaria (Sey). Biol. Bull., 136: 327-346.

EASTMAN-RECKS \& FINGERMAN, M., 1984, Effects of neuroendocrine tissue and cyclic AMP on ovarian growth in vivo and in vitro in the fiddler crab, Uca pugilator. Comp. Biochem. Physiol., 79A(4): 679-84.

EMMERSON, W. D., 1980, Induced maturation of the prawn Penaeus indicus. Mar. Ecol. Prog. Ser., 2: 121-131.

FINGERMAN, M. \& ROSEMBERG, M., 1988, Control of the melanophores of the crab Pachygrapsus marmoratus: release of pigment dispersing and pigment concentrating neurohormones by amines. Comp. Biochem. Physiol. 91C: 85-89.

HINSCH, G. W. \& BENNETT, D., 1979, Vitellogenesis stimulated by thoracic ganglion implants into destalked immature spider crabs, Libinia emarginata. Tissue \& Cell., 11(2): 345-351.

IDYLL, C. P., 1971, Induced maturation of ovaries and ova in pink shrimps. Commer. Fish. Rev., 33(4): 20.

KELLER, R. \& BAYER, J., 1968, Zur hyperglykamischen wirking von serotonin und ausgenstilextrakt beim flusskrebs Onconectes limosus. Z. Vgl. Physiol., 59: 7885 .

KULKARNI, G. K. \& FINGERMAN, M., 1992, Effects of 5-hydroxytryptamine agonists on ovarian development in the fiddler crab, Uca pugilator. Comp. Biochem. Physiol., 101C(2): 419-423.

KULKARNI, G. K., NAGABHUSHANAM, R. \& AMALDOSS, G., 1992, In vivo stimulation of ovarian development in the red swamp crayfish Procambarus clarkii (Girard), by 5-hydroxytryptamine. Invertebr. Reprod. and Dev., 21(3): 231-240.

MARTOSUBROTO, P., 1974, Fecundity of pink shrimp, Penaeus duorarum Bunkenroad. Bull. Mar. Sci., 24: 606627.

MATTSON, M. P. \& SPAZIANI, E., 1985, 5-hydroxitryptamine mediates release of molt-inhibiting hormone activity from isolated crab eyestalk ganglia. Biol. Bull., 169: 246-255.

MEUSY, J. J. \& PAYEN, G. G., 1988, Female reproduction in malacostracan crustacea. Zool. Sci., 5: 217-265.
NIE, N. H., HULL, C. H. \& JENKINS, J. G. P., 1975, SPSS Statistical Package for the Social Sciences. 2a ed., New York, McGraw Hill Books, 675p.

RAO, K. R. \& FINGERMAN, M., 1970, Action of biogenic amines on crustacean chromatophores. II. Analysis of response of erytrophores in fiddler crab, Uca pugilator, to indohalkylamines and eyestalk hormone. Comp. Gen. Pharmacol., 1: 117-126.

RICHARDSON, H. G., DEECARAMAN, M. \& FINGERMAN, M., 1991, The effect of biogenic amines on ovarian development in the fiddler crab, Uca pugilator. Comp. Biochem. Physiol., 99C(1/2): 53-56.

SAROJINI, R., NAGABHUSHANAM, R. \& FINGERMAN, M., 1995a, A neurotransmitter role for red-pigmentconcentrating hormone in ovarian maturation in the red swamp crayfish Procambarus clarkii. J. of Exp. Biol., 198: 1253-1257.

SAROJINI, R., NAGABHUSHANAM, R. \& FINGERMAN, M., 1995b, Mode of action of the neurotransmitter 5hydroxytryptamine in stimulating ovarian maturation in the red swamp crayfish Procambarus clarkii: An in vivo and in vitro study. J. of Exp. Biol., 271: 395-400.

TAKAYANAGI, H., YAMAMOTO, Y. \& TAKEDA, N., 1986, An ovary-stimulating factor in the shrimp, Paratya compressa. J. of Exp. Zool., 240: 203-209.

TSUZUKI, M. Y., ZIMMERMANN, S. \& CAVALLI, R. O., 1994, The use of silicone rings as a tagging methodology in the shrimps and prawns. In: Conference of World Aquaculture Society $X X Y^{\text {th }}$, New Orleans, USA, 12 to 18 , January, p. 285.

VAN HERP, F., 1992, Inhibiting and stimulating neuropeptides controlling reproduction in Crustacea. Invertebr. Reprod. and Dev., 22(1-3): 21-30.

WEITZMAN, M. C., 1964, Ovarian development and molting in the tropical land crab, Geocarcinus lateralis (Freminville). Am. Zoologist, 4: 329-330.

WELSH, J. W. \& SMITH, R. I., 1953, Laboratory Exercise in Invertebrate Physiology. [S. L.] Burgless Publishing Co., $126 \mathrm{p}$.

YANO, I., 1985, Induced ovarian maturation and spawning in greasyback shrimp, Metapenaeus ensis, by progesterone. Aquaculture, 47: 223-229. 